\title{
Towards In Vivo Monitoring of Ions Accumulation in Trees: Response of an in Planta Organic Electrochemical Transistor Based Sensor to Water Flux Density, Light and Vapor Pressure Deficit Variation
}

\author{
Davide Amato ${ }^{1}\left(\mathbb{D}\right.$, Giuseppe Montanaro $\left.{ }^{1, *} \mathbb{(}\right)$, Filippo Vurro ${ }^{2}$, Nicola Coppedé ${ }^{2}\left(\mathbb{D}\right.$, Nunzio Briglia ${ }^{1}$, \\ Angelo Petrozza ${ }^{3}$, Michela Janni ${ }^{2,4}$, Andrea Zappettini ${ }^{2}{ }^{\mathbb{D}}$, Francesco Cellini ${ }^{3}$ and Vitale Nuzzo ${ }^{1}$ (I) \\ 1 Università degli Studi della Basilicata, Via Nazario Sauro, 85, 85100 Potenza, Italy; \\ davide.amato@unibas.it (D.A.); nunzio.briglia@gmail.com (N.B.); vitale.nuzzo@unibas.it (V.N.) \\ 2 Istituto dei Materiali per l'Elettronica e il Magnetismo (IMEM-CNR)-Parco Area delle Scienze, \\ 43124 Parma, Italy; filippo.vurro@imem.cnr.it (F.V.); nicola.coppede@imem.cnr.it (N.C.); \\ michela.janni@ibbr.cnr.it (M.J.); andrea.zappettini@imem.cnr.it (A.Z.) \\ 3 ALSIA Centro Ricerche Metapontum Agrobios, s.s. Jonica 106, km 448, 2, 75010 Metaponto, Italy; \\ angelo.petrozza@alsia.it (A.P.); francesco.cellini@alsia.it (F.C.) \\ check for \\ updates \\ Citation: Amato, D.; Montanaro, G.; \\ 4 Istituto di Bioscienze e Biorisorse (IBBR-CNR), Via Amendola 165/A, 70126 Bari, Italy \\ * Correspondence: giuseppe.montanaro@unibas.it
} Vurro, F.; Coppedé, N.; Briglia, N.; Petrozza, A.; Janni, M.; Zappettini, A.; Cellini, F.; Nuzzo, V. Towards In Vivo Monitoring of Ions Accumulation in Trees: Response of an in Planta Organic Electrochemical Transistor Based Sensor to Water Flux Density, Light and Vapor Pressure Deficit Variation. Appl. Sci. 2021, 11, 4729. https: / / doi.org/10.3390/ app11114729

\section{Academic Editors:}

Dolores Parras-Burgos and Simone Morais

Received: 24 March 2021

Accepted: 19 May 2021

Published: 21 May 2021

Publisher's Note: MDPI stays neutral with regard to jurisdictional claims in published maps and institutional affiliations.

Copyright: (c) 2021 by the authors. Licensee MDPI, Basel, Switzerland. This article is an open access article distributed under the terms and conditions of the Creative Commons Attribution (CC BY) license (https:/ / creativecommons.org/licenses/by/ $4.0 /)$.

\begin{abstract}
Research on organic electrochemical transistor (OECT) based sensors to monitor in vivo plant traits such as xylem sap concentration is attracting attention for their potential application in precision agriculture. Fabrication and electronic aspects of OECT have been the subject of extensive research while its characterization within the plant water relation context deserves further efforts. This study tested the hypothesis that the response (R) of an OECT (bioristor) implanted in the trunk of olive trees is inversely proportional to the water flux density flowing through the plant (Jw). This study also examined the influence on $\mathrm{R}$ of vapor pressure deficit (VPD) as coupled/uncoupled with light. $\mathrm{R}$ was hourly recorded in potted olive trees for a 10-day period concomitantly with Jw (weight loss method). A subgroup of trees was bagged in order to reduce VPD and in turn Jw, and other trees were located in a walk-in chamber where $V P D$ and light were independently managed. $\mathrm{R}$ was tightly sensitive to diurnal oscillation of Jw and at negligible values of Jw (late afternoon and night) $\mathrm{R}$ increased. The bioristor was not sensitive to the VPD per se unless a light source was coupled to trigger Jw. This study preliminarily examined the suitability of bioristor to estimate the mean daily nutrients accumulation rate $(\mathrm{Ca}, \mathrm{K})$ in leaves comparing chemical and sensor-based procedures showing a good agreement between them opening new perspective towards the application of OECT sensor in precision agricultural cropping systems.
\end{abstract}

Keywords: bioristor; mineral nutrition; OECT; precision agriculture; PEDOT; sap concentration

\section{Introduction}

The management of mineral nutrition in agricultural systems contributes to the adequate nutrients availability for biochemical and structural functions in planta. Matching plant nutrient demand with nutrient soil supply (and availability) at short interval time (days or even hours) might help to avoid excessive (supply >>demand) or deficient (supply $<<$ demand) nutrition and in turn contributing to healthy plant and environment. A number of in-vivo sensors and non-touch image-based technologies are increasingly proposed within innovative agriculture to monitor plant traits including water status, diseases and minerals content [1-4]. Real time monitoring of nutrient availability in xylem sap is pivotal for that purpose and to minimize agriculture dependency on mineral fertilization and/or face nutrition stress. 
A relatively new set of organic electrochemical transistors (OECT) devices is emerging for the determination of physical and chemical characteristics of liquid samples and biological system including the ionic content [5-7]. Through mathematical models the change of the OECT device bulk conductivity allows the detection of the concentration of ions in solution making them increasingly used for bio-interfacing, bio-sensing, and electrophysiological recording [7-9]. Due to their ions' sensitivity and selectivity (e.g., K, $\mathrm{Mg}, \mathrm{Na}$ ) [10,11], OECT-based biosensors are promising tool within a smart plant nutrition management context. For example, current open-source application includes leaf nutrient content (sourced by foliar analysis) for the implementation of the monthly fertigation plan in olive [12]. Having a real time monitoring of ions carried in the sap as input data would strength that kind of app.

An OECT sensor (hereafter named bioristor) has been proposed for the in vivo real time monitoring of some physiological traits (including concentration of ions in the xylem sap) under variable environmental conditions and drought stress in herbaceous crops (e.g., tomato) [13-15]. However, due to the differences in the vascular system between herbaceous and trees [16], testing similar sensors for perennials is highly desirable.

The sensitivity of bioristor to positively charged ions (e.g., Ca, K) [15] led to a close relationship between the molar concentration of aqueous solutions and the sensor response (R). Moreover, previous work reported $\mathrm{R}$ and $V P D$ and stomatal conductance highly correlated $\left(R^{2}=0.82\right)$ in tomato $[14,15]$ under a $V P D$ ranging within $0-0.8 \mathrm{kPa}$. The $V P D$ is a well-known driver of transpiration (and in turn of sap flow) which often lags behind (or occurs in advance) of VPD particularly under high VPD [17,18]. In addition, values of $V P D$ in cultivated areas (e.g., Mediterranean-type) usually peak at 3-4 KPa [19], hence testing an OECT sensor in a perennial crop under Mediterranean growing conditions and in relation to plant transpiration would integrate current knowledge on OECT sensor.

Concentration of xylem sap $\left(\mathrm{Ci}, \mathrm{mol} \mathrm{m}^{-3}\right)$ at any instant is satisfactorily approximated by the ratio of the flux density of solutes ( $\mathrm{Js}, \mathrm{mol} \mathrm{m}^{-2} \mathrm{~s}^{-1}$ ) and that of (volumetric) water $\left(\mathrm{Jw}, \mathrm{m}^{3} \mathrm{~m}^{-2} \mathrm{~s}^{-1}\right.$ ) entering the xylem [20]. Values of Js depend on several factors including nutrients uptake by roots, xylem tissues loading-unloading, nutrients delivery and utilization along the transportation pathway [21]. In addition, roots might passively (diffusion) and/or actively uptake ions [22]. A mass flow of ions into root also occurs because they are dragged in by Jw (activated by transpiration flux) and/or because Jw induces a continuous removal of the ions at membrane interface after they have been released into the xylem lumen $[23,24]$. Concerning the flow of water in the xylem $(\mathrm{Jw})$, by recalling the Poiseuille's Law and based on the cohesion theory, it depends on plant conductance and is driven by the hydrostatic soil-plant-atmosphere pressure gradient $(\Delta \mathrm{P})$ which is generated by diffusion of water vapor from leaf to the atmosphere in response to the leaf-to-air VPD [20]. Hence, $\mathrm{Jw}$ is influential on $\mathrm{Ci}$ because it contributes to the load of ions (proportionally to the soil solution concentration and the reflection coefficient) and because it operates as the solvent of xylem sap [20].

It appears that while fabrication and electronic aspects of OECT have been the subject of roughly extensive research, its characterization within a plant water relation and ion transport mechanisms context deserve further efforts. Therefore, this study tested the hypothesis that the response of bioristor $(R)$ which is candidate to measure Ci would be inversely proportional to water flux density (Jw).

Within a mechanistic approach $V P D$ drives the water flux $(V P D \rightarrow \mathrm{Jw})$. Water flux is also triggered by light availability due to its influence on stomatal behavior and in turn on transpiration [25]. Under outdoor conditions changes of $V P D$ occur simultaneously with that of other meteorological variables (e.g., light) making their effect(s) on transpiration (and on R) difficult to separate. To infer new information on the influence of VPD per se on $\mathrm{R}$, this study examined whether the response of the bioristor to changing environmental conditions is dominated by VPD per se or by water flux. For this purpose, olive trees growing in a walk-in chamber were subjected to various combinations of light dark and $V P D$ cycles. 
In order to progress towards the application of OECT sensor for precision agriculture, this study also examined the suitability of the bioristor to estimate ion accumulation rate in leaves. Considering that accumulation of ions in a certain time period would be proportional to the flux density of water and sap concentration in the same time period (i.e., $\mathrm{Jw} \times \mathrm{Ci}$ ), that accumulation was calculated in parallel using Ci inferred from the OECT sensor and from actual analytically determined tissue concentration.

\section{Materials and Methods}

\subsection{Plant Material and Experimental Design}

The experiment has been conducted in a greenhouse at the ALSIA-CRMA research center, Southern Italy $\left(40^{\circ} 23^{\prime} 31.4^{\prime \prime} \mathrm{N}, 16^{\circ} 47^{\prime} 10.9^{\prime \prime} \mathrm{E}\right)$ using 12 olive trees (Olea europaea L., var. Picholine). Trees were 2 years old and grown in a $6.2 \mathrm{~L} \mathrm{PVC} \mathrm{pot} \mathrm{and} \mathrm{were} \mathrm{fertilized}$ at 15 days interval before the experiment (total of 4 applications) using $3 \mathrm{~g} / \mathrm{pot}$ of NPK fertilizer 14.7.14 (Slowenne 212, Valagro Spa, Atessa, Italy). Each pot was covered with a plastic film and aluminum foil to minimize warming and direct evaporation of water from the soil. bioristors were installed on the 2nd of April (hereafter 0 day after sensor installation, DASI). At 6 DASI (7 p.m.) the whole plant canopy of 6 trees was enclosed in a plastic bag $(130 \mathrm{~L})$ to minimize the VPD of the air surrounding the canopy. Bag closure was ensured by wrapping the bag around the trunk with tight sealing film (Parafilm-M, Sigma Aldrich, St. Louis, MI, USA). After 9 days (15 DASI, 7 p.m.), bags were removed.

\subsection{Determination of Jw}

Each potted tree was positioned on a digital scale ( $5 \mathrm{~g}$ resolution) (FieldScale, Phenospex, Heerlen, Netherlands) programmed to measure and record the weight every 15 min interval. Irrigation was supplied daily to fully restore water consumption using tap water in order to maintain soil moisture close to $85 \%$ of field capacity. The daily water consumption ( $\mathrm{g} \mathrm{d}^{-1}$ ) was calculated as the difference of weigh recorded at 7 p.m. of two consecutive days. Plant water consumption (W) $\left(\mathrm{mol} \mathrm{H}_{2} \mathrm{O} \mathrm{h}^{-1}\right)$ was calculated hourly throughout the $24 \mathrm{~h}$ interval from 00:00 to 23:00 $\mathrm{h}$ solar time as the difference between two consecutive weights measured at $1 \mathrm{~h}$ interval. Plant transpiration (E) $\left(\mathrm{mol} \mathrm{H}_{2} \mathrm{O} \mathrm{m}^{-2} \mathrm{~h}^{-1}\right)$ was determined as $\mathrm{W} / \mathrm{LA}$ where LA was the plant leaf area $\left(\mathrm{m}^{2}\right)$.

The initial LA was determined by counting the total number of leaves per plant and considering a mean area (see below) of $3.53 \mathrm{~cm}^{2}$ per leaf. The number of leaves newly developed during the experiment was determined by counting at the end of the trial the leaves standing on the new part of the shoots. For mean leaf area determination, 3 bulk samples (total 200 leaves) were collected from 3 trees not included in the trial, leaves were then pictured, and the surface area of each single bulk was determined via image analysis (ImageJ, https:/ /imagej.nih.gov/ij/). Then a linear correlation between the number of leaves of each bulk and the corresponding leaf area was employed to satisfactorily $\left(R^{2}=0.99\right)$ estimate the mean area of a single leaf as the slope value. Leaf area was assumed to linearly develop during the experimental period.

Values of water flux density $\left(\mathrm{Jw}, \mathrm{mol} \mathrm{m}^{-2} \mathrm{~h}^{-1}\right)$ was calculated as W/TA where TA was the trunk cross sectional area $\left(\mathrm{m}^{2}\right)$ estimated by measuring the trunk diameter close to the point where the bioristor was installed.

\subsection{OECT Installation}

Bioristor (i.e., biological resistor) sensors were installed across trunk at approx. $40 \mathrm{~cm}$ from the ground following the procedure reported in [15]. Briefly, bioristor is composed by two PEDOT:PSS (poly-3,4-ethylenedioxythiophene polystyrene sulfonate) functionalized threads: a main channel of the transistor and a gate of the transistor that, subjected to a positive voltage, generates the electric field that pushes the cations present in the sap in the polymer deposited on the main wire, changing its conductivity [13]. Sensors were prepared and inserted in two trunk holes $(\varnothing=0.8 \mathrm{~mm}, 5 \mathrm{~mm}$ distance) drilled with a dremel allowing them to fully cross the trunk. The constant voltage on the source-drain 
channel was of $-0.1 \mathrm{~V}$ while the voltage applied at the gate was $1 \mathrm{~V}$. Figure 1 shows the setup of the bioristor.

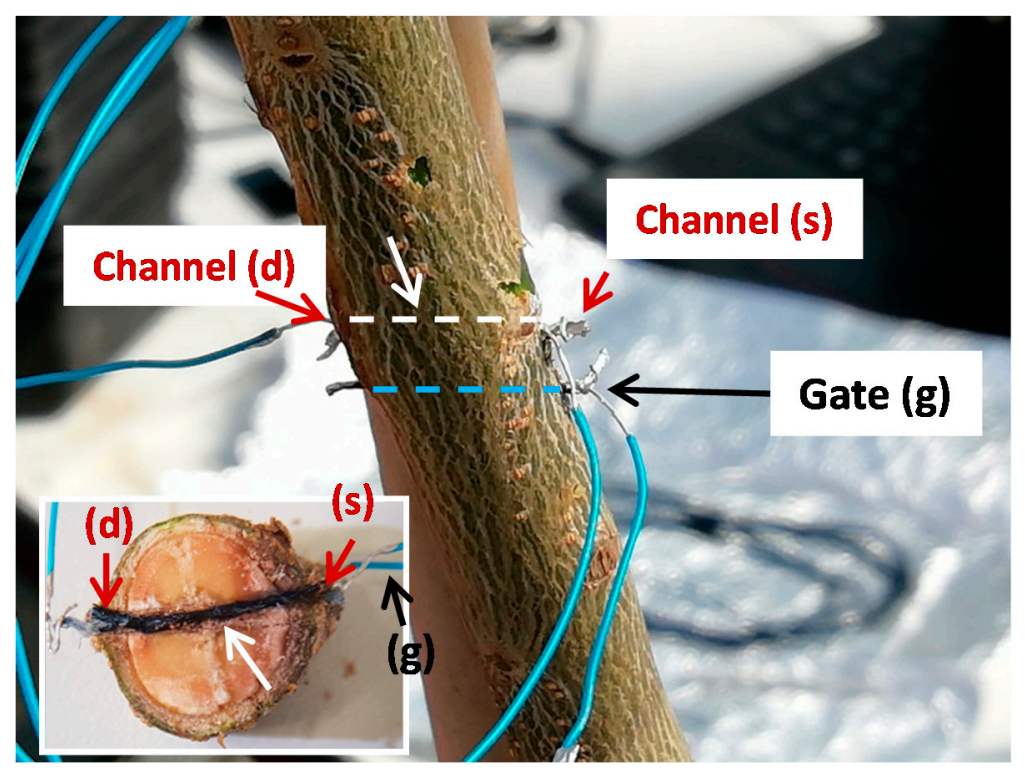

Figure 1. Side view of the olive tree trunk showing the setup of the bioristor with channel and gate wires which were connected to the multifunction I/O device for supply, record and store of electrical currents. In the inset: illustrative trunk cross sectional view (at the channel insertion point) showing the textile fiber functionalized with Pedot:PSS (white arrow).

All bioristors were then connected to a multichannel digital analogic converter $\mathrm{I} / \mathrm{O}$ (USB-6343, National Instruments, Austin, TX, USA) to supply voltages controlled by a home-made software which, measure and store in the PC the values of electrical currents. Values of the OECT sensor response (R) was determined according to Coppedè et al. [13] as $\mathrm{R}=\left(\mathrm{I}_{\mathrm{dS}}-\mathrm{I}_{\mathrm{dS} 0}\right) / \mathrm{I}_{\mathrm{dS} 0}$, where $\mathrm{I}_{\mathrm{ds} 0}$ is the current at gate voltage equal to zero, and $\mathrm{I}_{\mathrm{dS}}$ was the resulting current at the voltage equal 1 . For data analysis covering successive days, data of $\mathrm{R}$ before plotting were scaled (min-max normalization, $(0,1)$ range) to ensure comparisons between days of experiment.

\subsection{Walk-in Chamber Experiment}

To examine the effect of light and VPD on R, 3 additional trees were located in a $2 \times 3 \times 2.5 \mathrm{~m}$ walk-in chamber (KW Apparecchi Scientifici, Monteriggioni-Siena, Italy). The chamber was equipped with 6 lamps (mod. APO 6 OrtoLED42-6, INDOORLINE s.r.l., Garzigliana, TO, Italy). Each lamp had 90 led ensuring an illumination equivalent to a light PAR intensity of approx. $1100 \mu \mathrm{mol} \mathrm{m} \mathrm{m}^{-2} \mathrm{~s}^{-1}$. Inside the chamber the regulation of parameter (air temperature, humidity) was operated once it deviated $\pm 10 \%$ of the target value. Trees inside the chamber were separately positioned on 3 additional digital scales and their $\mathrm{W}, \mathrm{E}$, and Jw determined as reported above.

\subsection{Ions Accumulation Rate}

\subsubsection{Bioristor Based Estimates}

The mean daily accumulation rate $\left(\mathrm{mg} \mathrm{day}^{-1}\right)$ of $\mathrm{Ca}$ and $\mathrm{K}$ in newly developing leaves was calculated as follow:

$$
\text { accumulation rate }=\mathrm{N} \_\mathrm{Jw} \times[\mathrm{R}] \times \mathrm{N} \_\mathrm{LA} / \mathrm{n}\left(\mathrm{mg} \mathrm{day}^{-1}\right)
$$

where $\mathrm{N} \_\mathrm{Jw}$ was the hourly water flux density suppling the new leaf area reported in volumetric values (m h-1) measured over $\mathrm{n}(17)$ days of experiment; [R] was the hourly nutrient concentration estimted from $\mathrm{R}$ values converted in $\mathrm{mol} \mathrm{m}^{-3}$ of $\mathrm{K}$ and $\mathrm{Ca}$ [15]; 
N_LA, was the leaf area $\left(\mathrm{m}^{2}\right)$ of the new developing leaves. The $\mathrm{N} \_\mathrm{Jw}$ and [R] where reported to daily values by summing the diurnal 24 records collected over the 0:23 $\mathrm{h}$. The flux Jw ( $\mathrm{mol} \mathrm{m}^{-2} \mathrm{~h}^{-1}$ ) was partitioned between new developing ( $\left.\mathrm{N} J \mathrm{~J}\right)$ and old leaves according to their leaf area as destructively determined at the end of the experiment under the assumption they had similar E.

\subsubsection{Analytical Determination}

Leaves collected for final leaf area determination from 6 plants were dried in a ventilated oven $\left(65^{\circ} \mathrm{C}\right.$, minimum $48 \mathrm{~h}$ till constant weight) to determine the total dry matter per plant (DM). An aliquot of dry matter was used for mineral element (me) (i.e., Ca e K) concentration ([me]) determination according to Celano et al. [26]. The mean daily accumulation rate was determined considering the number of days of the experiment $(\mathrm{n})$ by means of the formula $\mathrm{DM} \times[\mathrm{me}] / \mathrm{n}$.

\subsection{Meteorological Data}

Air temperature $\left({ }^{\circ} \mathrm{C}\right)$ and relative humidity $(\% \mathrm{RH})$ were monitored through digital probes (mod. CS215, Campbell Scientific Inc., Logan, UT, USA) positioned close to the canopy ( $\times 1$ a tree). Probes were connected to a datalogger (CR10X, Campbell Scientific Inc., UT, Logan, USA) programmed to record a 60 s interval and to compute the mean value every $15 \mathrm{~min}$. Additional probes were used to monitor air temperature and $\mathrm{RH}$ inside the bagged canopy. In order to avoid direct contact between probes and eventual condensed water, the probes were put in a plastic tube open at the bottom. A total of 6 probes per treatment were monitored. The $V P D$ was then calculated from air temperature and $\mathrm{RH}$ values [27].

\subsection{Data Analysis}

The statistical analysis, plotting and fitting were by OriginPro 9.3 (OriginLab Corporation, Northampton, MA, USA).

\section{Results}

The response of OECT biosensors fabricated with organic electronic materials are increasingly tested for sensing ions or molecules within various applications and research (e.g., healthcare, environmental monitoring, healthcare products, water and food test) $[6,28,29]$. Nanosized transducers such as OECT based sensors are also relevant for agriculture mainly because of the role of ions and molecules in plant structure and function and food quality [30,31]. Here, an OECT based sensor installed in a living trunk has been examined to test its response to the amount of water flowing through the plant and to environmental factors (VPD and light) contributing to open up novel avenues for precision in plant mineral nutrition.

\subsection{Sensitivity of the Bioristor to Diurnal Change of Environmental Conditions}

The sensor response $(\mathrm{R})$ showed a typical circadian pattern confirming previous studies employing the bioristor in annual crops $[13,14]$. In the present study, $R$ trends have been analyzed against the changes of Jw and transpiration. It was observed that $\mathrm{R}$ quickly declined from early morning $(\sim 6: 00 \mathrm{~h})$ concomitantly with the beginning of plant transpiration flux (Figure 2). As soon as plant transpiration rate begun to decline (approx. 1300-1500 h), R trend reversed and continuously increased until approx. 19:00-20:00 h when the transpiration reached minimum values (Figure 2). Thereafter, while transpiration continued to sit at the minimum, $\mathrm{R}$ further increased and highest values were recorded around midnight or just before the beginning of the transpiration cycle of the next day (Figure 2). 


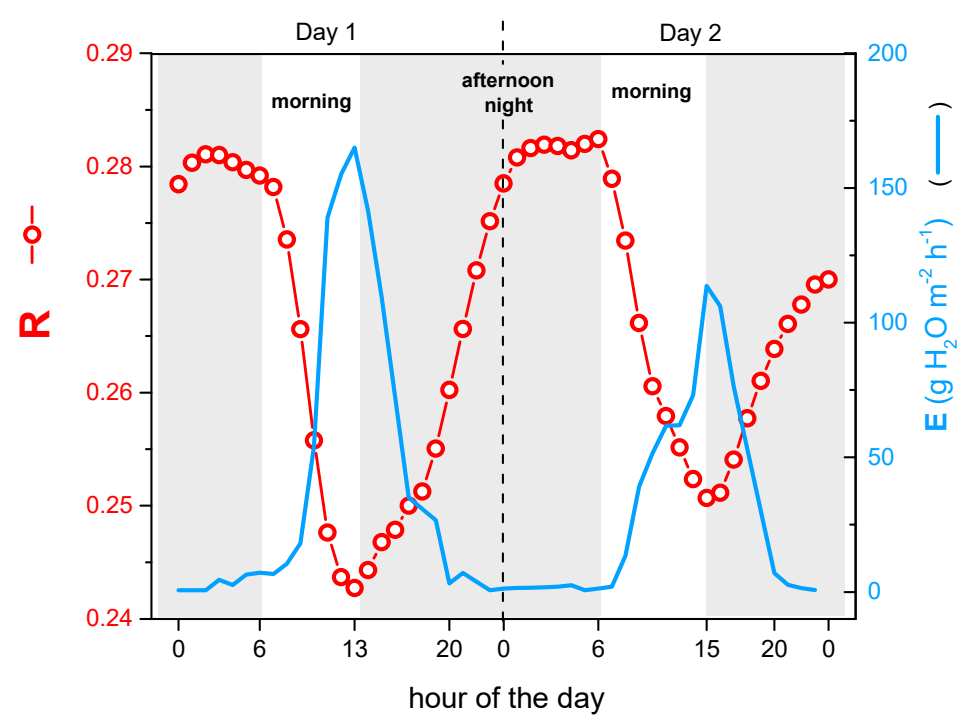

Figure 2. Diurnal variations of $\mathrm{R}(\bigcirc)$ and plant transpiration $(\mathrm{E})$ (continuous line) recorded over two consecutive days. The vertical dashed line separates the two consecutive days (8 and 9 April).

To explain increasing $R$ values observed at null or very low transpiration (Figure 2) the main mechanisms of ions and water load into xylem should be evoked. Although the weight of active and passive loading mechanism(s) of ions (and other solutes) into the xylem has not yet clearly defined [32], the xylem loading of ions might be uncoupled from that of water because plant's membrane is differentially permeable to water and ions [20,32]. Xylem conduits are non-selective structures, hence water and solutes flow in the xylem at the same velocity through the mass flow driven by the $\Delta \mathrm{P}$ independently by the osmotic pressure, excepting under saturating conditions when transpiration ceases (e.g., night or at very low $V P D$ ), or in case of low-transpiring organs (e.g., fruit,) [20-33].

Under non-limited water condition and according to the constancy of water flow through the plant [34], almost the whole volumetric water flux density taken up by root is transpired by leaf and in turn the same volume of water is loaded into xylem. Hence, variation in the Jw calculated through plant transpiration is a reliable proxy for volumetric water uptake from soil and loaded into xylem. Values of plant transpiration (E) (Figure 2) were consistent with those of sap flow (referred per unit of leaf area) measured in potted olive trees under similar VPD [35].

Variations of $\mathrm{R}$ appeared to be proportional to those of plant transpiration particularly during the first part of the day (from $\sim 6 \mathrm{~h}$ to $\sim 13 \mathrm{~h}$, hereafter referred as "morning") (Figure 2). Figure 2 also shows a substantial late "afternoon" and "night" variation (increase) of $\mathrm{R}$ which was independent of $\mathrm{E}$ (and thus of $V P D$ ). Considering that $\mathrm{E}$ depends on leaf-to-air VPD and canopy conductance [20], $\mathrm{R}$ would correlate with VPD as suggested by previous reports [15]. Such a correlative link between $V P D$ and $\mathrm{R}$ might be influenced by the eventual hysteretic pattern of $\mathrm{R}$. That is, diurnal $\mathrm{R}$ might move in a hysteresis loop when plotted against $V P D$ with the hysteretic magnitude differing day-by-day depending on $V P D$ level (Figure 3).

Results show that in a warm day with $V P D$ peaking at approx. $3 \mathrm{KPa}$, data of $\mathrm{R}$ collected a.m. had different slope compared to that measured p.m. (Figure 3C-D). While in a mild day (max VPD at $\sim 1.5 \mathrm{KPa}$ ) the slopes of $\mathrm{R}$ data measured a.m. and p.m. were more comparable (Figure 3A-B). This might be explained considering the possible time lag effect of VPD on diurnal pattern of certain traits (e.g., sap flow, transpiration) $[17,36,37]$ related to sap ionic concentration and in turn to R. It appears that disentangling the diurnal pattern of $\mathrm{R}$ in relation to Jw (which is triggered by VPD), would contribute to expand previous knowledge on the response of OECT sensors to the surrounding environment (see below). The VPD-R linear correlations and the evidence that $V P D$ triggers the xylem stream [20] suggest that the OECT would monitor the xylem tissue although it was in contact with 
xylem and phloem as per installation procedure, however a specific experiment is needed to test it.
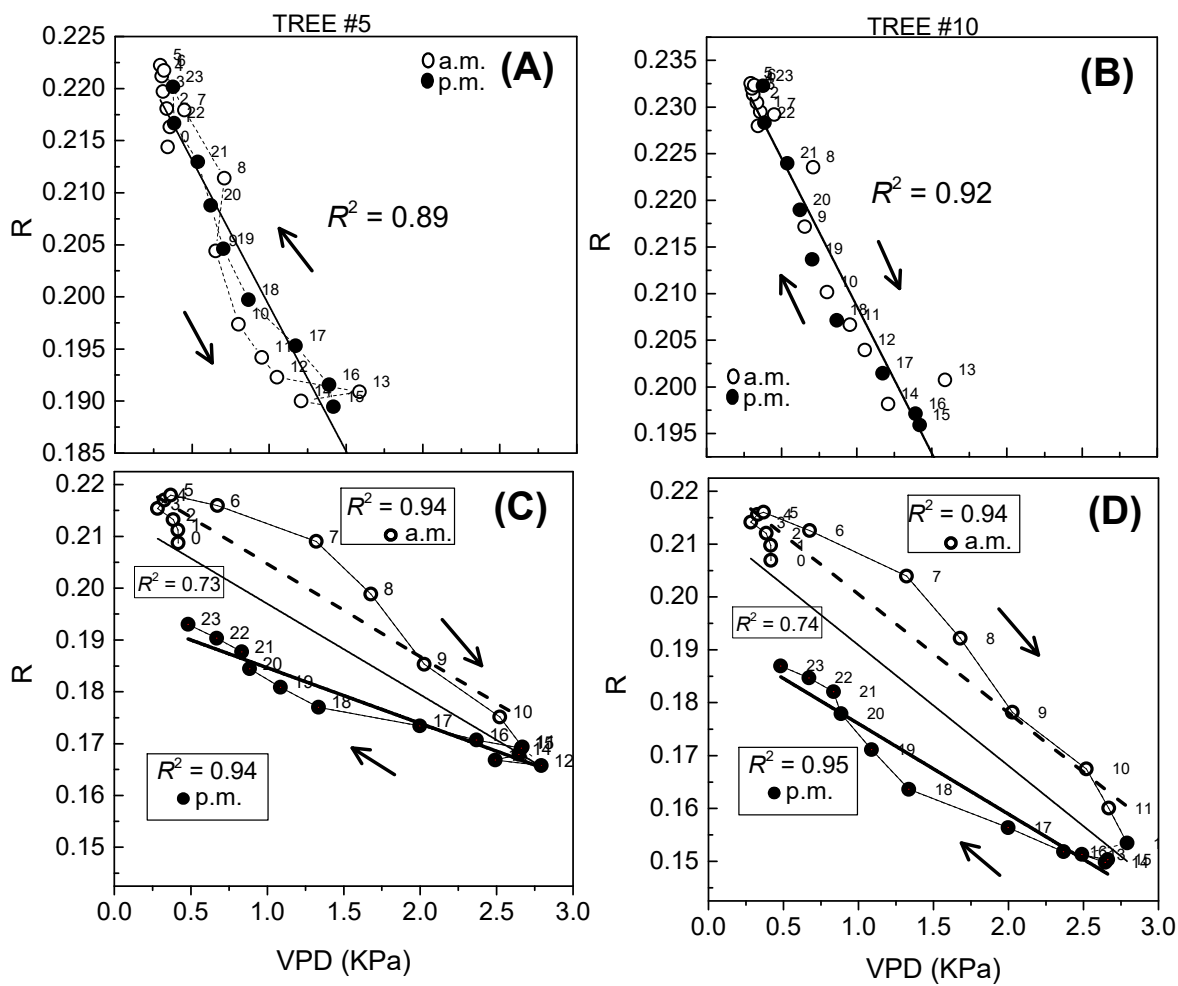

Figure 3. Example of diurnal variation of $\mathrm{R}$ in tree $\# 5(\mathbf{A}, \mathbf{C})$ and $\# 10$ (B,D) plotted against VPD recorded during days with maximum high $\operatorname{VPD}(\mathbf{C}, \mathbf{D})$ and low $(\mathbf{A}, \mathbf{B})$ highlighting the hysteresis of R between a.m. $(\bigcirc)$ and p.m. $(\bullet)$ data. Note that a.m. and p.m. values in each panel were pooled before fitting (continuous mild line) and $R^{2}$ determination. For panel $(\mathbf{C}, \mathbf{D})$ additional fittings were performed separately for a.m. (bold continuous line) and p.m. (bold dashed line) data. The numbers close to the symbol indicate the day hour when data have been recorded. Arrows indicate the time course of the day from 0 to $23 \mathrm{~h}$.

Values of xylem sap concentration depend on the ratio between the solutes flux density (Js) and that of water (Jw) [38], hence factors affecting Js and Jw would be influential on output of any device measuring xylem sap concentration. This study was undertaken to test whether the bioristor response $\mathrm{R}$ (which is an OECT-based proxy for xylem sap concentration) changes according to Jw. Particularly, considering that in the xylem there is no membrane selectivity and that at high Jw it dominates upon other parameters influencing the xylem ions load (e.g., temperature, carriers) $[20,24]$, it is expected that $R$ would change (decline) with increasing Jw.

Accounting for the diurnal variation of $\mathrm{R}$ (Figure 2), the "morning" and the "afternoonnight" daytime parts were identified. The "morning" was characterized by a fast increase of Jw from negligible values early morning ( $\sim$ a.m.) to maximum ones recoded at around midday which induced a consistent decay of R (Figure 4). Incidentally, Figure 4 shows again the hysteretic behavior of R between a.m. and p.m. data. The Jw values detected during the "afternoon-night" stage were in general lowest than that measured "morning" and follow an exponential pattern, however the highest and often sharp increase of $\mathrm{R}$ was detected late in the afternoon (e.g., after 18:00 h) when $\mathrm{Jw}<0.5 \mathrm{~mol} \mathrm{~m}^{-2} \mathrm{~s}^{-1}$ (Figure 4). This result is difficult to discuss due to very limited data existing on this specific issue, however it is line with the non-linear correlation between Jw and xylem sap concentration reported in the literature for soybean plant [39]. Under increasing transpiration (as during "morning") the load of solutes into the stele of xylem at root region is dominated by ions dragged in by the water flux density Jw $[21,24]$ Hence, the increasing Jw during the "morning" 
(Figure 4) induced a consistent reduction of R because of a conceivably "dilution" of the sap concentration dependent on water moving with increasing transpiration stream [24].

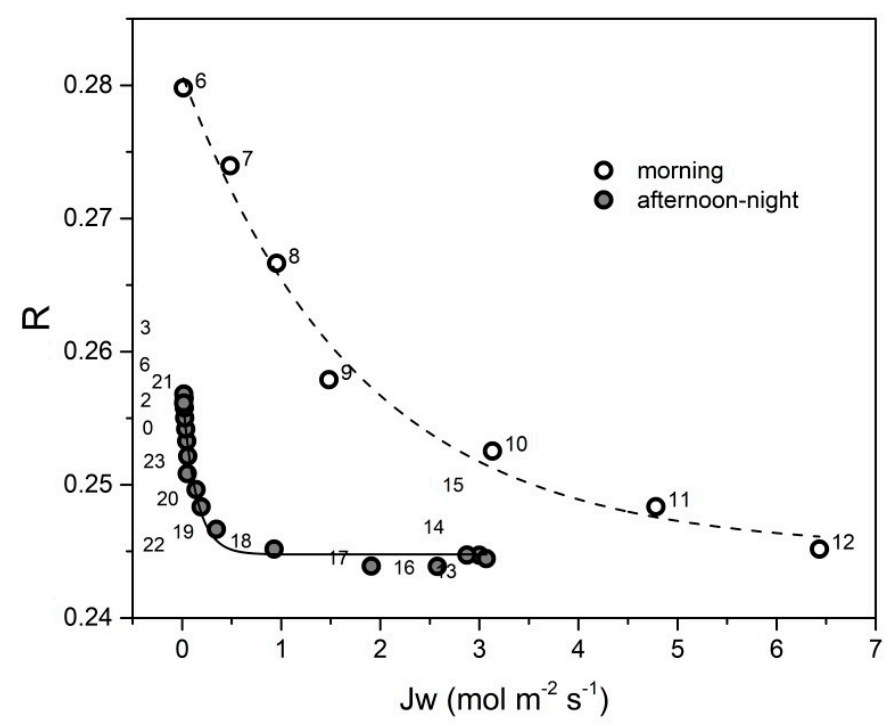

Figure 4. Example of the influence of Jw on the diurnal variation of R recorded during $(\bigcirc)$ "morning" and $(\bullet)$ "afternoon-night". Labels indicate the hour of the day, note that $1-5 \mathrm{~h}$ refer to the following day.

By contrast, when Jw is null or negligible (because of low $\Delta \mathrm{P}$ ) (e.g., during night) solutes are loaded mainly by passive diffusion or even active transport [32]. However, active transport requires availability of newly synthesized sugars/carbohydrates which are poorly available during night (White et al., 2012). Hence, the increase of $R$ observed when transpiration is negligible (i.e., approx. from $18-19$ p.m. to $4-5$ a.m. of the the next day) (Figure 4) might reflect the increase of xylem sap concentration due to osmotic root pressure and unload of nutrients from saturated xylem tissues [23].

Data collected in this study allow to generalize the partitioning of $\mathrm{R}$ to Jw according to the daytime. Correlative information collected over an 8-day period reported in Figure 5 confirms a non-linear decay of R with increasing Jw during the "morning" (Figure 4; [38]).

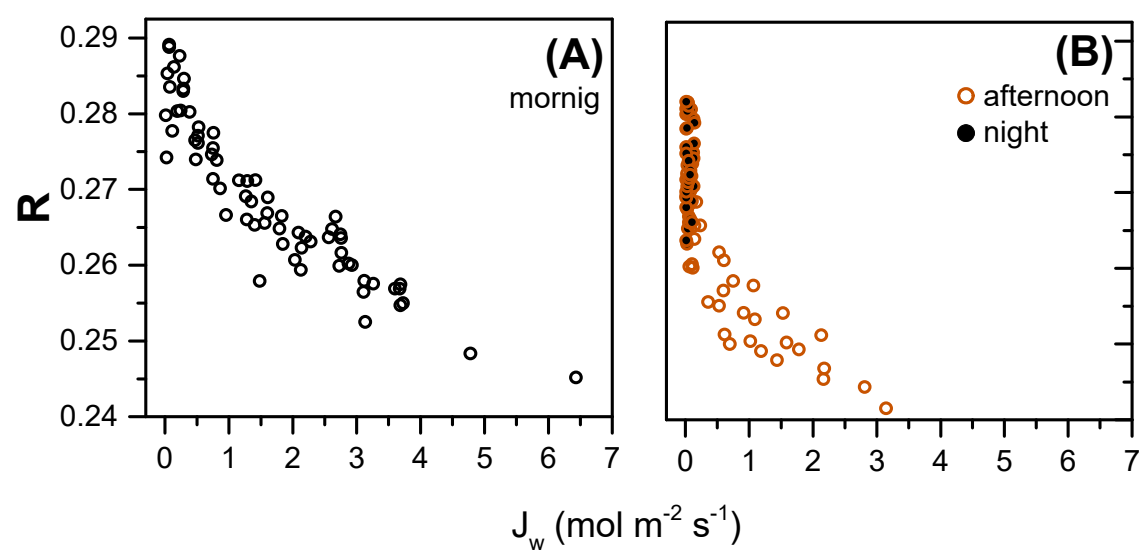

Figure 5. Correlation between $\mathrm{R}$ and Jw over a time series (8 consecutive days) recorded in tree \#5 during the (A) "morning" and (B) "afternoon" and "night" stages. The "morning" stage begin early when transpiration start (approx. 6:00 h) and end at time n (approx. 13-15 h), when the difference between transpiration measured at time $n+1$ and that measured at time $\mathrm{n}$ is $<0$. The "afternoon-night" span from hour $n+1$ till the 4:00-5:00 $\mathrm{h}$ of the next day before the beginning of the new transpiration cycle. 
The analysis of the "afternoon-night" data confirms the approx. $10 \%$ increase of $\mathrm{R}$ at negligible Jw (Figure 5) mainly because of the lack of the "dilution" effect which is reasonably expected to be caused by a sustained Jw. To allow comparisons across days and trees, values of $R$ have been normalized (min-max, 0:1 range) in analogy to a study that compared daily fruit transpiration throughout the growing season [39]. Normalized $R$ responded to Jw according to the part of the day considered (i.e., morning, afternoon-night) (Figure 6). It is confirmed also that the pattern of the "morning" dataset (increasing Jw) was substantially similar to that of the "afternoon-night" but without the vertical harm generated when Jw was stably negligible (Figures 5 and 6).

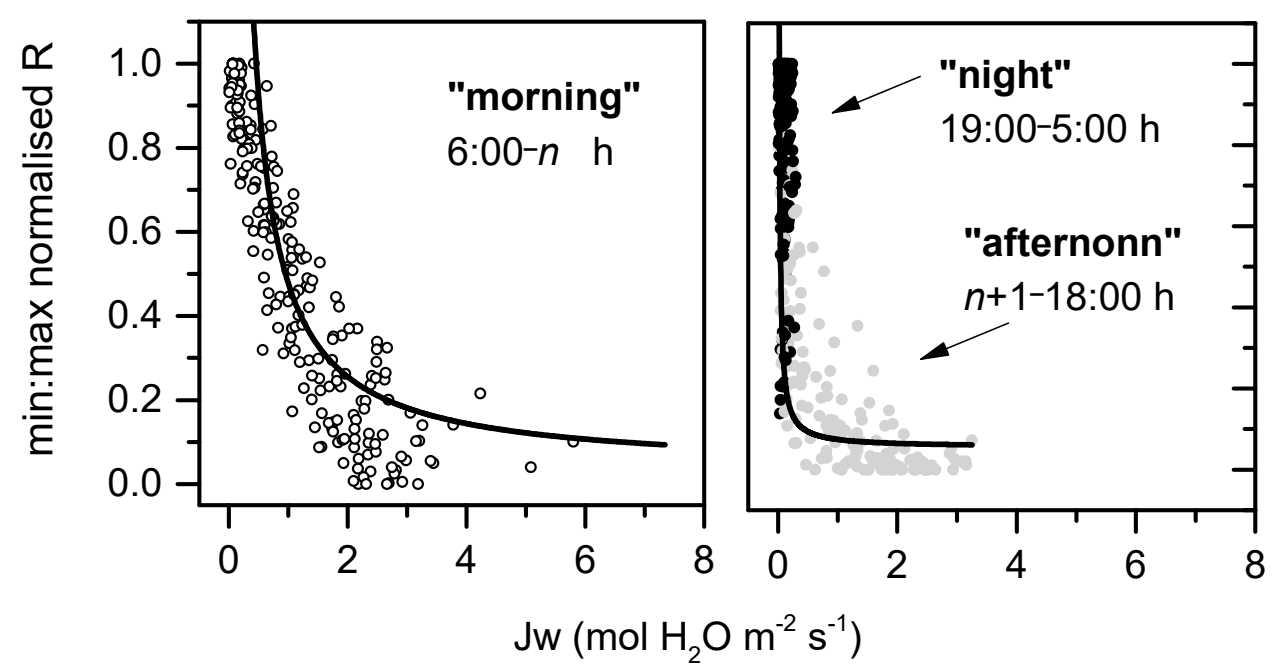

Figure 6. Correlation between R signal and the water flux density (Jw) hourly measured in olive trees during (top panel) "morning" $(\bigcirc)$ and (bottom panel) "afternoon" (•, grey filled) and "night" $(\bullet$, black filled). The $n+1 \mathrm{~h}$ indicates the time of the day (between 13 and $15 \mathrm{~h}$ ) corresponding to that when Jw become lower than that measured at time $n$. Note that scatters have been fitted using the model $y=a+b / x$ consistent with that of the ions' concentration expected in the xylem, lines are illustrative only.

\subsection{Response of Bioristor to Water Flux Density}

The main driving force of the flux density of water $(\mathrm{Jw})$ is the $V P D$, hence it is expected a reduction of Jw upon a reduction of $V P D$. To test the influence of Jw on $\mathrm{R}$, a group of trees was bagged to bring the air surrounding the canopy close to the saturation point and in turn the VPD close to zero. The bagging method has been documented to effectively reduce $V P D$ at plant or branch and fruit scale by reducing RH with negligible impact on air temperature $[30,34,40]$.

The VPD promptly responded to the bag application (19 h, 5 DASI) and removal (19 h, 15 DASI) mainly through variation of relative humidity which approximated $90 \% \mathrm{RH}$ (not shown). On average, the daily VPD of the air surrounding the bagged olive canopy was reduced by $80 \%$ compared to that of control trees (Figure 7 ). This induced a consistent reduction of daily water consumption in bagged trees compared to control ones (Figure 8).

Throughout the 10-day bagging experiment an $80 \%$ reduction of the $V P D$ was recorded which induced a $60 \%$ reduction in Jw (Figure 7 ).

Under no stomatal limitation, the causal chain $V P D \rightarrow \mathrm{Jw} \rightarrow \mathrm{R}$ anticipates the indirect influence of the VPD on $\mathrm{R}$ as mediated by Jw because Jw is proportional to $\triangle \mathrm{P}$ (hydrostatic soil-plant-atmosphere pressure gradient) generated by the leaf-to-air VPD. Figure 9 shows diurnal oscillations of $\mathrm{R}$ recorded in some succeeding days with different VPD and consequently different Jw. It is confirmed that reducing VPD reduced Jw and in turn increased $\mathrm{R}$. In addition, $\mathrm{R}$ increased by $8-12 \%$ during the time when Jw was negligible (from late afternoon until early morning of the following day). The increasing $\mathrm{R}$ signal at negligible Jw conceivably reflects the absence of sap dilution induced by water flux and 
the increasing root pressure usually occurring overnight when plants have almost null transpiration $[22,23,41]$.

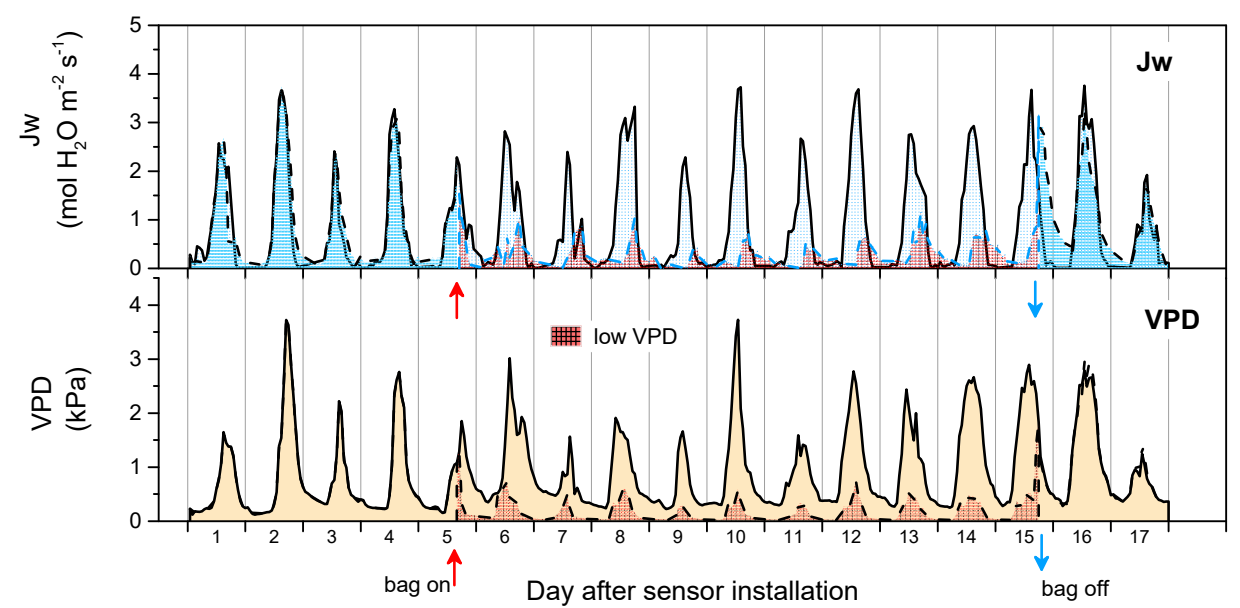

Figure 7. Values of $V P D$ and Jw (at trunk level) measured throughout the experiment in olive trees under control and low $V P D$ (grid gray filled). The dashed line refers to the tree enclosed in a transparent plastic bag to induce the low VPD. Time of bag on and off were indicated by $\uparrow$ and $\downarrow$ arrows, respectively.

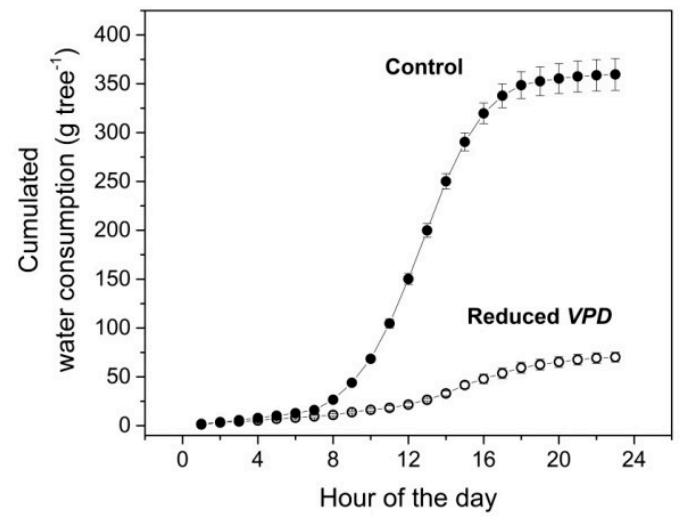

Figure 8. Cumulated diurnal plant transpiration measured in trees under control $(\bullet)$ and reduced $V P D(\bigcirc)$ by means of bag application. Each point is the average of 6 trees, bars $( \pm \mathrm{SE})$ are visible when larger than symbol. Data relates to day 8th of experiment.

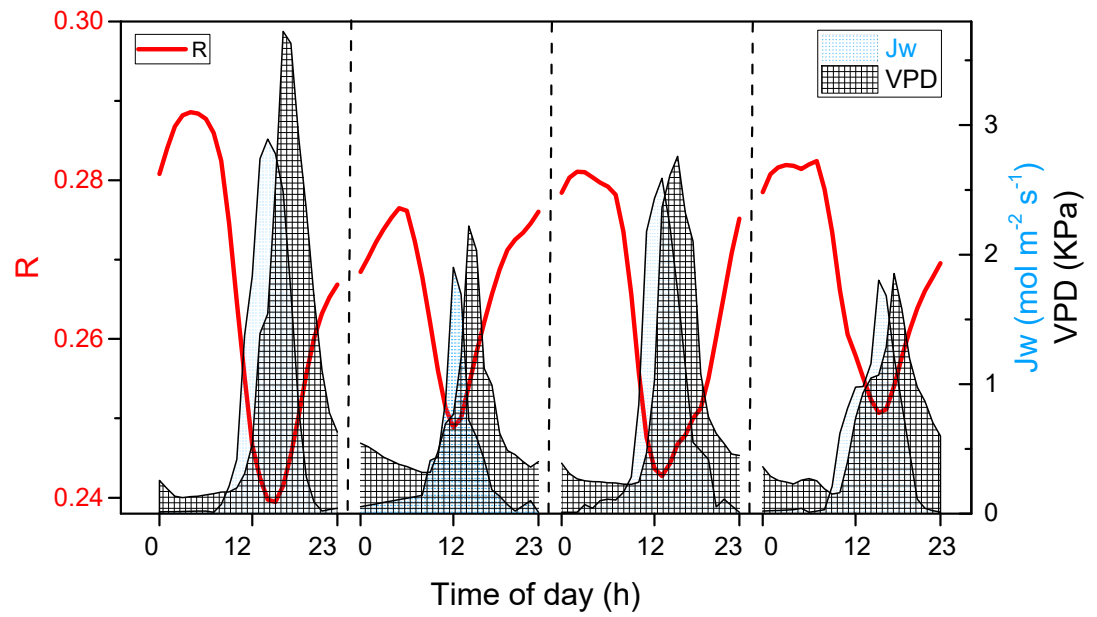

Figure 9. Oscillation of diurnal bioristor signal $\mathrm{R}$ (continuous line), water flux density Jw (blue filled area) and $V P D$ (grid filled area) recorded over 4 consecutive days separated by vertical dashed lines. 
Figure 9 shows also the general correspondence of $\mathrm{R}$ and Jw patterns during the morning daytime and the alignment between maximum pick of JW and the minimum one of R. The plot highlights that the Jw lags in advance to VPD (Figure 9) confirming a known aspect of water relations $[18,42,43]$ suggesting that Jw would be a robust parameter to consider for OECT-based sensors analysis.

\subsection{Disentangling Bioristor Response to Environmental Conditions}

Under outdoor conditions the changes of VPD occur simultaneously with that of other meteorological variables (e.g., light, wind) making their effect(s) on transpiration very difficult to separate. However, the present study aimed at supporting that Jw is the main driver of $\mathrm{R}$, because it is a proxy of xylem sap concentration which depends on the Js/Jw ratio. Hence, trees were exposed to combinations between stable/variable VPD and on/off light. Figure 10 reports the values of R and Jw recorded in a tree standing in the walk-in chamber during 3 consecutive days. Results show that $R$ responded to change of Jw induced by light-on period while the increase of VPD per se was not influential when it was uncoupled from light (i.e., during dark). This result is in line with the response of sap flow to variations of VPD and radiation observed in Populus spp. [43].

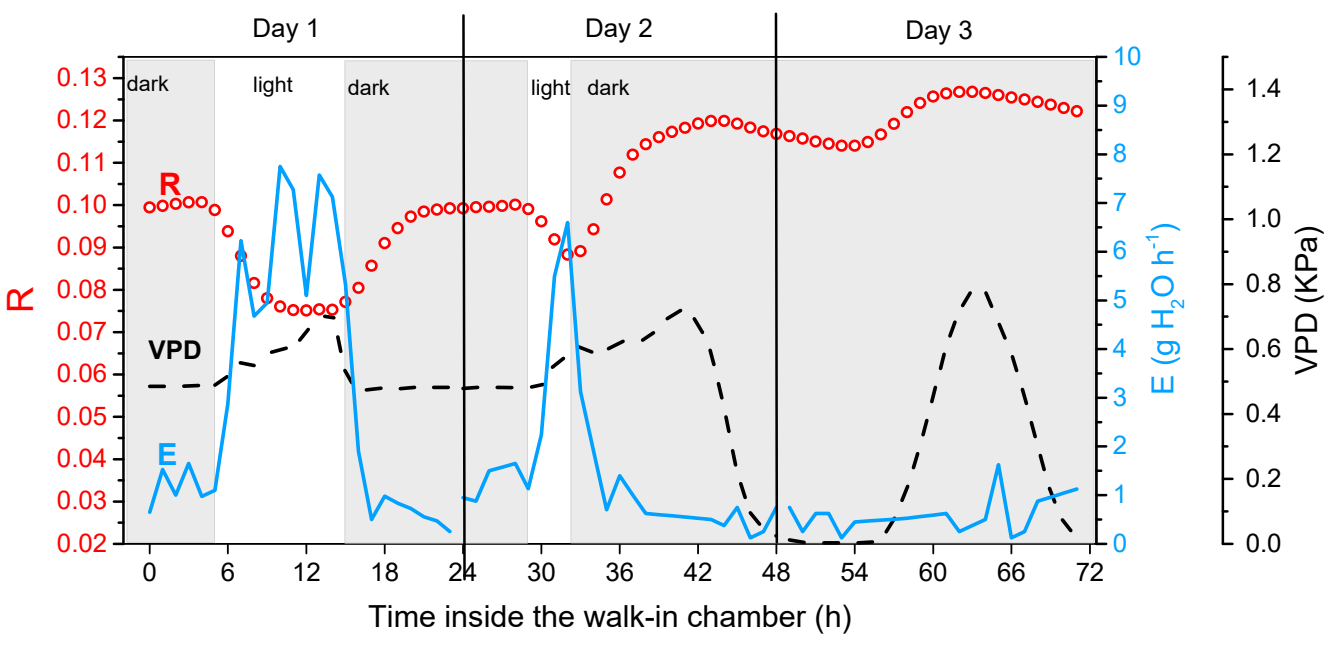

Figure 10. Diurnal pattern of bioristor signal $\mathrm{R}$ (circle), transpiration (E, continuous line) and VPD (dashed line) recorded over 3 consecutive days inside a walk-in chamber with variable light/dark and $V P D$ conditions. The grey filled area indicates the dark period. Here below a detailed description of variations occurring during the 3 days analyzed.

Notably, as for the second day, also in the third day the superimposed increasing VPD during dark was not influential on $\mathrm{E}$ and in turn on $\mathrm{R}$. This might be explained considering that stomata were conceivably closed during the light-off period due to the direct effect of light on stomatal opening [44].

On the third day R slightly increased (Figure 10) likely because (i) of the lack of the "dilution" effect of Jw and (ii) of the conceivable increased root pressure due to increased sap concentration determined by passive and active components of Js, moreover, increasing $\mathrm{R}$ might be related to reduced ions load by xylem tissues which likely saturated [21,23].

First day, light-on was set for 10 h (from 5 a.m. to 3 p.m.) and was off (dark) for the remaining time of the day. The VPD was set to increase concurrently to the light-on period miming its behavior under outdoor condition. In that first day, $\mathrm{R}$ oscillations were in line with data collected outside the chamber identifying the "morning" and "afternoon-night" stages during the light-on and light-off time, respectively.

Second day, the light-on period was restricted to just $4 \mathrm{~h}$ (from 5 a.m. to 9 a.m.) while the $\overline{V P D}$ was set to progressively increase also during the dark period until 8 p.m. As 
expected, $\mathrm{R}$ responded to change of Jw induced by light period while the increase of $V P D$ was not influential when it was uncoupled with light.

Third day, light was kept off for $24 \mathrm{~h}$, while the VPD was set to cycle from approx. 10:00 to 20:00 $\mathrm{h}$. Values of transpiration sited close to negligible values during the whole $24 \mathrm{~h}$ period, and consequently values of $\mathrm{R}$ remained roughly stable (at highest value) without showing neither the "morning" nor the "afternoon-night" oscillations.

\subsection{Perspective on the Use of Bioristor to Monitor Leaf Mineral Accumulation}

This study also examined whether the OECT sensor might be potentially used for estimation of nutrients (i.e., $\mathrm{Ca}$ and $\mathrm{K}$ ) accumulation in newly growing leaves. Considering that Jw might causes the non-diffusive xylem load of ions at root scale and their solubilization in the sap (as discussed above), the sensitivity of the bioristor to changes of $\mathrm{Jw}$ (Figures 9 and 10) anticipates the promising capability of the bioristor to precisely estimate ions accumulation in plant organs. Apart from concentration of nutrients in the feeding xylem sap, nutrients accumulation depends on several factors including xylem-phloem mobility of the nutrient, growth of the organ, use of nutrients along the transportation path [24]. Within the experimental period (17 days) leaf area significantly increased by approx. $30 \%$ and $15 \%$ of the initial value in trees with regular (control) and reduced Jw, respectively (Figure 11A). That increment of leaf area corresponded to approx. $21 \mathrm{~g}$ dry matter per tree of new leaves (control) while it was significantly 50\% lower (Student's $t$-test, $p=0.05)$ in trees under reduced Jw. The Ca and K nutrient content in that dry matter was determined destructively (dry matter analysis) and through the OECT based estimates (Figure 11B) showing a good agreement between the two methods. The non-linearity between the two methods might be explained considering that the nutrient accumulation depends on several factors (see above), while OECT-based method here adopted employed only the ion sap concentration and water flux density carrying the nutrients. Coefficients used to convert $\mathrm{R}$ values in $\mathrm{Ca}$ an $\mathrm{K}$ molar concentrations were retrieved from [15] who measured under lab condition the values of $\mathrm{R}$ in response to salt solutions of known concentrations, of course these coefficients need to be validated in in vivo systems. Improved version of the bioristor accounting for in vivo condition would refine the sensor output, however, it might be preliminarily stated that the bioristor could be a promising tool for monitoring of nutrients accumulation within a precision agriculture domain.
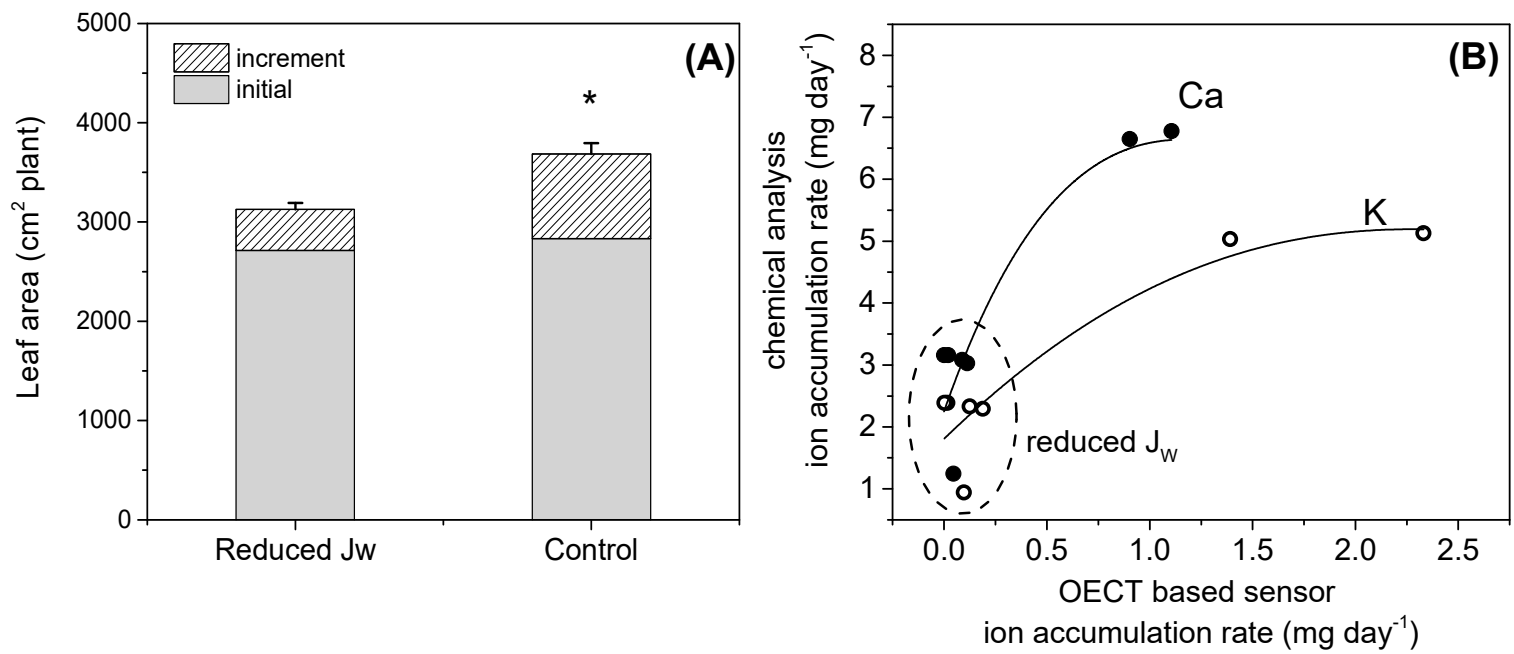

Figure 11. (A) Average leaf area per plant $( \pm S E)$ measured at beginning and the end of the experiment in trees under regular (control) and reduced Jw. The increment of leaf area has been determined as the difference between initial and final values. Comparing the increment of leaf area between treatments, * indicates statistically significant differences. (B) Accumulation rate (mg day 1$)$ of $\mathrm{Ca}(\bullet)$ and $\mathrm{K}(\bigcirc)$ as determined through the OECT values of sap concentration and through the chemical analysis of the dry mater of new developed leaves with a 2 weeks' period. Note that dash circled values have been sampled from trees under reduced Jw. 


\section{Conclusions}

This paper demonstrated that the signal response of an OECT sensor (a candidate proxy of sap ionic concentration) installed in the trunk of a perennial tree is inversely proportional to the water flux density $(\mathrm{Jw})$ flowing-through the transpiring tree. Under negligible plant transpiration, the signal increased likely reflecting the putative increase of sap concentration due to increased osmotic pressure and lack of the "dilution" effect operated by Jw. The diurnal response of an OECT based sensor should be partitioned according to the part of the day (i.e., "morning", "afternoon", "night") also to account for possible hysteresis of its pattern due to changing interaction between Jw and VPD. Based on results gained in the walk-in chamber it could also be concluded that the VPD per se is not influential on the OECT signal unless a light source is coupled to trigger plant transpiration. Experimental results on the suitability of the sensor-based data to estimate ion accumulation in leaves open new perspectives for its application in mineral nutrition in agriculture.

Author Contributions: G.M., V.N., A.P. and M.J. conceptualized the experiment. D.A. and F.V. set up the experiment; D.A. and N.B. carried out the experiment; D.A., N.B. and F.V. carried out the data analyses; D.A., G.M. and N.B., wrote the manuscript. A.P., F.C., V.N., M.J., N.C. and A.Z. reviewed the manuscript. G.M., F.C., A.Z. obtained the funding and F.C. provided the access to the facilities. All authors have read and agreed to the published version of the manuscript.

Funding: D.A. was supported by a Smart Specialization "Industria 4.0" fellowship programme funded by Basilicata Region) of the Program "Cities and Landscapes: Architecture, Archaeology, Cultural Heritage, History and Resources" at Università degli Studi della Basilicata. This paper was partially funded by the 2014-2020 Rural Development Programme of Basilicata Region (Misura 16.2, ORGOLIO LUCANO, CUP C38I19000050006).

Institutional Review Board Statement: Not applicable.

Informed Consent Statement: Not applicable.

Data Availability Statement: The datasets generated during and/or analyzed during the current study are available from the corresponding author on reasonable request.

Acknowledgments: Authors thank A. Mossuto (Natura Informatica) for technical assistance.

Conflicts of Interest: The authors declare no conflict of interest.

\section{References}

1. Tomkiewicz, D.; Piskier, T. A plant based sensing method for nutrition stress monitoring. Precis. Agric. 2012, 13, 370-383. [CrossRef]

2. Briglia, N.; Montanaro, G.; Petrozza, A.; Summerer, S.; Cellini, F.; Nuzzo, V. Drought phenotyping in Vitis vinifera using RGB and NIR imaging. Sci. Hortic. 2019, 256, 108555. [CrossRef]

3. Lu, J.; Yang, T.; Su, X.; Qi, H.; Yao, X.; Cheng, T.; Zhu, Y.; Cao, W.; Tian, Y. Monitoring leaf potassium content using hyperspectral vegetation indices in rice leaves. Precis. Agric. 2020, 21, 324-348. [CrossRef]

4. Fallon, B.; Yang, A.; Lapadat, C.; Armour, I.; Juzwik, J.; Montgomery, R.A.; Cavender-Bares, J. Spectral differentiation of oak wilt from foliar fungal disease and drought is correlated with physiological changes. Tree Physiol. 2020, 40, 377-390. [CrossRef]

5. Zeglio, E.; Eriksson, J.; Gabrielsson, R.; Solin, N.; Inganäs, O. Highly Stable Conjugated Polyelectrolytes for Water-Based Hybrid Mode Electrochemical Transistors. Adv. Mater. 2017, 29, 1605787. [CrossRef]

6. Rivnay, J.; Inal, S.; Salleo, A.; Owens, R.M.; Berggren, M.; Malliaras, G.C. Organic electrochemical transistors. Nat. Rev. Mater. 2018, 3, 17086. [CrossRef]

7. Gentile, F.; Vurro, F.; Picelli, F.; Bettelli, M.; Zappettini, A.; Coppedè, N. A mathematical model of OECTs with variable internal geometry. Sens. Actuators A Phys. 2020, 304, 111894. [CrossRef]

8. Tarabella, G.; Villani, M.; Calestani, D.; Mosca, R.; Iannotta, S.; Zappettini, A.; Coppedè, N. A single cotton fiber organic electrochemical transistor for liquid electrolyte saline sensing. J. Mater. Chem. 2012, 22, 23830-23834. [CrossRef]

9. Gentile, F.; Delmonte, D.; Solzi, M.; Villani, M.; Iannotta, S.; Zappettini, A.; Coppedè, N. A theoretical model for the time varying current in organic electrochemical transistors in a dynamic regime. Org. Electron. 2016, 35, 59-64. [CrossRef]

10. Coppedè, N.; Villani, M.; Gentile, F. Diffusion Driven Selectivity in Organic Electrochemical Transistors. Sci. Rep. 2015, 4, 4297. [CrossRef] [PubMed] 
11. Coppedè, N.; Tarabella, G.; Villani, M.; Calestani, D.; Iannotta, S.; Zappettini, A. Human stress monitoring through an organic cotton-fiber biosensor. J. Mater. Chem. B 2014, 2, 5620-5626. [CrossRef] [PubMed]

12. Alcaide Zaragoza, C.; González Perea, R.; Fernández García, I.; Camacho Poyato, E.; Rodríguez Díaz, J.A. Open source application for optimum irrigation and fertilization using reclaimed water in olive orchards. Comp. Electron. Agric. 2020, $173,105407$. [CrossRef]

13. Coppedè, N.; Tarabella, G.; Villani, M.; Calestani, D.; Iannotta, S.; Zappettini, A. n in vivo biosensing, biomimetic electro-chemical transistor with applications in plant science and precision farming. Sci. Rep. 2017, 7, 16195. [CrossRef] [PubMed]

14. Janni, M.; Coppede, N.; Bettelli, M.; Briglia, N.; Petrozza, A.; Summerer, S.; Vurro, F.; Danzi, D.; Cellini, F.; Marmiroli, N.; et al. In Vivo Phenotyping for the Early Detection of Drought Stress in Tomato. Plant Phenomics 2019, 2019, 1-10. [CrossRef] [PubMed]

15. Vurro, F.; Janni, M.; Coppedè, N.; Gentile, F.; Manfredi, R.; Bettelli, M.; Zappettini, A. Development of an In Vivo Sensor to Monitor the Effects of Vapour Pressure Deficit (VPD) Changes to Improve Water Productivity in Agriculture. Sensors 2019, 19, 4667. [CrossRef]

16. Evert, R.F.; Esau, K. Structure and Development of the Plant Body-An Overview in Esau's Plant Anatomy: Meristems, Cells, and Tissues of the Plant Body: Their Structure, Function, and Development; Evert, R.F., Ed.; Wiley-Interscience: Hoboken, NJ, USA, 2006; pp. 1-13.

17. Bai, Y.; Zhu, G.; Su, Y.; Zhang, K.; Han, T.; Ma, J.; Wang, W.; Ma, T.; Feng, L. Hysteresis loops between canopy conductance of grapevines and meteorological variables in an oasis ecosystem. Agric. For. Meteorol. 2015, 214-215, 319-327. [CrossRef]

18. Takagi, K.; Tsuboya, T.; Takahashi, H. Diurnal hystereses of stomatal and bulk surface conductances in relation to vapor pressure deficit in a cool-temperate wetland. Agric. For. Meteorol. 1998, 91, 177-191. [CrossRef]

19. Montanaro, G.; Dichio, B.; Xiloyannis, C. Significance of fruit transpiration on calcium nutrition in developing apricot fruit. J. Plant Nutr. Soil Sci. 2010, 173, 618-622. [CrossRef]

20. Nobel, P.S. Solutes in Physiochemical and Environmental Plant Physiology; Elsevier Academic Press: Cambridge, MA, USA, 2005; pp. 99-169.

21. White, P.J. Ion Uptake Mechanisms of Individual Cells and Roots: Short-Distance Transport in Marschner's Mineral Nutrition of Higher Plants; Marschner, P., Ed.; Elsevier: Cambridge, MA, USA, 2012; pp. 7-47.

22. White, P.J. Ion Transport in Encyclopedia of Applied Plant Sciences; Thomas, B., Murphy, D.J., Murray, B.G., Eds.; Academic Press: Cambridge, MA, USA, 2017; pp. 238-245.

23. Steudle, E. Water uptake by plant roots: An integration of views. Plant Soil 2000, 226, 45-56. [CrossRef]

24. White, P.J. Long-Distance Transport in the Xylem and Phloem in Marschner's Mineral Nutrition of Higher Plants; Marschner, P., Ed.; Elsevier: Cambridge, MA, USA, 2012; pp. 49-70.

25. Grantz, D.A.; Moore, P.H.; Zeiger, E. Stomatal responses to light and humidity in sugarcane: Prediction of daily time courses and identification of potential selection criteria. Plant Cell Environ. 1987, 10, 197-204.

26. Celano, G.; Dichio, B.; Montanaro, G.; Nuzzo, V.; Palese, A.; Xiloyannis, C. Distribution of dry matter and amount of mineral elements in irrigated and non-irrigated olive trees. Acta Hortic. 1999, 474, 381-384. [CrossRef]

27. Goudriaan, J.; van Laar, H.H. Modelling Potential Crop Growth Processes in Current Issue in Production Ecology; Goudriaan, J., van Laar, H.H., Eds.; Kluwer Academic Publishers: Dordrecht, The Netherlands, 1994; Volume 2, pp. 127-128. ISBN $9780792332190-238$.

28. Liao, J.; Si, H.; Zhang, X.; Lin, S. Functional Sensing Interfaces of PEDOT:PSS Organic Electrochemical Transistors for Chemical and Biological Sensors: A Mini Review. Sensors 2019, 19, 218. [CrossRef]

29. Mohankumar, P.; Ajayan, J.; Mohanraj, T.; Yasodharan, R. Recent developments in biosensors for healthcare and biomedical applications: A review. Measurement 2021, 167, 108293. [CrossRef]

30. Konwarh, R.; Sharma, P.L. Nanosensor Platforms for Surveillance of Plant Pathogens and Phytometabolites/Analytes vis-à-vis Plant Health Status in Micro and Nano Technologies, Nanomaterials for Agriculture and Forestry Applications; Husen, A., Jawaid, M., Eds.; Elsevier: Amsterdam, The Netherlands, 2020; pp. 357-385.

31. Kundu, M.; Krishnan, P.; Kotnala, R.; Sumana, G. Recent developments in biosensors to combat agricultural challenges and their future prospects. Trends Food Sci. Technol. 2019, 88, 157-178. [CrossRef]

32. Siebrecht, S.; Herdel, K.; Schurr, U.; Tischner, R. Nutrient translocation in the xylem of poplar-diurnal variations and spatial distribution along the shoot axis. Planta 2003, 217, 783-793. [CrossRef]

33. Montanaro, G.; Dichio, B.; Lang, A.; Mininni, A.N.; Xiloyannis, C. Fruit calcium accumulation coupled and uncoupled from its transpiration in kiwifruit. J. Plant Physiol. 2015, 181, 67-74. [CrossRef]

34. Honert, T.H.V.D. Water transport in plants as a catenary process. Discuss. Faraday Soc. 1948, 3, 146-153. [CrossRef]

35. Dichio, B.; Montanaro, G.; Sofo, A.; Xiloyannis, C. Stem and whole-plant hydraulics in olive (Olea europaea) and kiwifruit (Actinidia deliciosa). Trees 2012, 27, 183-191. [CrossRef]

36. Bai, Y.; Li, X.; Liu, S.; Wang, P. Modelling diurnal and seasonal hysteresis phenomena of canopy conductance in an oasis forest ecosystem. Agric. For. Meteorol. 2017, 246, 98-110. [CrossRef]

37. Zeppel, M.J.B.; Murray, B.R.; Barton, C.; Eamus, D. Seasonal responses of xylem sap velocity to VPD and solar radiation during drought in a stand of native trees in temperate Australia. Funct. Plant Biol. 2004, 31, 461-470. [CrossRef]

38. Fiscus, E.L. Determination of Hydraulic and Osmotic Properties of Soybean Root Systems. Plant Physiol. 1977, 59, 1013-1020. [CrossRef]

39. Montanaro, G.; Dichio, B.; Lang, A.; Mininni, A.N.; Nuzzo, V.; Clearwater, M.J.; Xiloyannis, C. Internal versus external control of calcium nutrition in kiwifruit. J. Plant Nutr. Soil Sci. 2014, 177, 819-830. [CrossRef] 
40. Domec, J.-C.; Noormets, A.; King, J.S.; Sun, G.; McNulty, S.G.; Gavazzi, M.J.; Boggs, J.L.; Treasure, E.A. Decoupling the influence of leaf and root hydraulic conductances on stomatal conductance and its sensitivity to vapour pressure deficit as soil dries in a drained loblolly pine plantation. Plant Cell Environ. 2009, 32, 980-991. [CrossRef]

41. Köhler, B.; Raschke, K. Loading of Ions into the Xylem of the Root in the Apoplast of Higher Plants: Compartment of Storage, Transport and Reactions; Sattelmacher, B., Horst, W.J., Eds.; Springer: Dordrecht, The Netherlands, 2007; pp. 181-200.

42. Roddy, A.; Dawson, T. Novel patterns of hysteresis in the response of leaf-level sap flow to vapor pressure deficit. Acta Hortic. 2013, 991, 261-267. [CrossRef]

43. Wang, H.; He, K.; Li, R.; Sheng, Z.; Tian, Y.; Wen, J.; Chang, B. Impact of time lags on diurnal estimates of canopy transpiration and canopy conductance from sap-flow measurements of Populus cathayana in the Qinghai-Tibetan Plateau. J. For. Res. 2016, 28, 481-490. [CrossRef]

44. Meidner, H.; Mansfield, T.A. Stomatal responses to illumination. Biol. Rev. 1965, 40, 483-508. [CrossRef] 